\title{
Effects of MATLAB Supported Learning on Students' Motivation on Learning Applied Mathematics: A Case of Mechanical Engineering Students, Wolkite University
}

\author{
Eyasu Gemechu ${ }^{1, *}$, Kassa Michael², Mulugeta Atinafu² \\ ${ }^{1}$ Department of Mathematics, Faculty of Natural Science and Computation, Wolkite University, Wolkite, Ethiopia \\ ${ }^{2}$ Department of Science and Mathematics Education, Addis Ababa University, Addis Ababa, Ethiopia
}

Email address:

gmeyasu@gmail.com (E. Gemechu)

*Corresponding author

\section{To cite this article:}

Eyasu Gemechu, Kassa Michael, Mulugeta Atinafu. Effects of MATLAB Supported Learning on Students' Motivation on Learning Applied Mathematics: A Case of Mechanical Engineering Students, Wolkite University. Education Journal. Vol. 10, No. 1, 2021 , pp. 1-7. doi: $10.11648 /$ j.edu.20211001.11

Received: December 29, 2020; Accepted: January 14, 2021; Published: January 28, 2021

\begin{abstract}
Mathematics is one of an important tool for engineering and technology students to solve day-to-day problems in life in general and problems posed to them in engineering and technology courses in particular. To help them capture mathematical concepts use of appropriate instructional approach is equally important factor. Instruction supported by technological software is reported to be useful in general terms, but the importance on motivation is debated. To this end, Quasi-experiment research was conducted in Wolkite University to investigate MATLAB Software supported learning and students' motivation in learning Applied Mathematics II. Different instructional approaches: MATLAB Software supported traditional lecture method and MATLAB supported collaborative method were established for this purpose. Two intact classes, Mechanical engineering groups 1 and 2, were selected using a simple random sampling technique, each of which took specific intervention. The numbers of the students involved were initially 30 and 29 respectively. Both pre and post motivation Likert Scale items were prepared and administered to the respondents before and after treatment respectively. The results of the study show that there is no significant mean difference in students' motivation for learning mathematics between the two groups. Besides, there is no significant mean difference between the components of motivation except for intrinsic and extrinsic motivation that seeks further scrutiny. Reasons for non-significant difference were highlighted some of which included a lack of experience, and a lack of motivation to learn mathematics itself. The ability to manipulate technological software and access could also be noted that lay context at the center.
\end{abstract}

Keywords: MATLAB Supported Learning Method, Students Motivation, Applied Mathematics

\section{Introduction}

Mathematics is one important tool for engineering and technology students to solve day-to-day problems in life in general and problems posed to them in engineering and technology courses [1] in particular. Motivation of the learner towards mathematics matters and is useful to address it. Technology might also contribute to motivation of students toward learning activities in STEM subjects [2]. To increase students' motivation one of the ways is to mediate instruction through technology. It helps students not only to concretize abstract concepts but also to configure concepts in a multidimensional ways [3] and abundant research suggests that students' motivation is associated with teacher beliefs and technology integration practices [4]. It is further highlighted that ICT can escalate students motivation in self-directed learning aspects when using online learning resources [5].

It is obvious that motivation is an individual's internal status towards something. The internal status determines the strength of the relationship between input and output of the individual behavior. Motivation refers to the reason for an initiative of an individual's behavior toward a particular goal, to take part in a certain activity or serve as a fuel to achieve one goal [3]. It is considered as an important factor in affecting students' 
academic performance. Motivation is a term used to describe the direction, intensity, initiation, and persistence of human behaviors [6]. If the motivation is ignored, teaching will be ineffective. So, in order to better understand the relationship between the instructional methods used in the classroom, students' motivation and learning mathematics in this study, the researchers reviewed related works of literature on students' motivation, particularly from expectancy, value and affective point of view [7].

Pintrich and De Groot proposed a model called a cognitive model for motivation [8]. In this model, they clearly indicated that the intensity of an individual's motivation determines to execute good or bad learning strategies. In support of this idea, there are works of literature that indicate motivation and learning strategies affect student's learning performance [9, 10]. Successful learning of students is consistently associated with their motivation [11].

Literature classified components of motivation into value, expectancy and affect [12]. On top of this, the researchers indicate that the issue of value can be influenced by intrinsic goal orientation, extrinsic goal orientation, and task value [9]. An issue of expectancy is affected by self-efficacy for learning and beliefs about learning whereas the affective aspect of motivation is affected anxiety $[9,13]$.

Intrinsic motivation refers to do something based on his/her inherent interest to be satisfied. This means the individual does not depend on the outside stimulus. Extrinsic motivation refers to do something based on an external to initiatives to gain something. Most of the time, it is supported by external stimuli to do a given activity. The stimuli can be appreciation, praise, reward and so forth $[14,15]$. The basic difference between intrinsic and extrinsic motivation is doing something because of inherently interesting and external outcomes [15]. Intrinsic motivation results in high-quality learning and creativity in the teaching-learning process than extrinsic motivation [14]. However, both intrinsic and extrinsic motivations are equally important [15].

\section{Statement of the Problem}

These days, most of the scientific researcher point out mathematical software, whether being in a programming way or teaching the topics in various effects (like graph, computation, etc.) can facilitate not only the comprehension of mathematical concepts but also increasing the motivation of students and the trust of oneself [16]. A paradigm shift regarding appropriate implementation of technology in education is also felt to be necessary to ensure a successful 21 st century classroom and to set up students for success in their future careers [17].

A study reveals that the utilization of software technology increases students' motivation. There is a positive relationship between technology and students' motivation, and also there is a direct association between students' motivation and learning mathematics [18]. Technology increases motivation and retention of subject matters [19].

However, technology might contribute to motivation of students toward learning activities, whose effect might be different across different types of schools [2] and types of technologies as adequate provision of required technology facilities which are effectively utilized for instructional facilitation [20] is important. Thus, in this study, the researchers used MATLAB software supported learning in combination with collaborative methods and traditional lecture methods to explore how these increase students' motivation to learn mathematics.

\section{General Objective}

The general objective is to explore the effect of the use of MATLAB supported learning on students' motivation. The following are the specific objectives of the study:

1. To investigate whether there is a significant difference in the motivation of students in Applied Mathematics using MATLAB supported learning in combination with a traditional lecture method and MATLAB supported learning in combination with collaborative method.

2. To examine the motivation and components of motivation of those with and without MATLAB supported learning.

\section{Research Hypothesis}

Base on the statement of the problem the following research hypotheses were developed to carry out the study:

1. There is no significant mean difference between pre-motivation and post-motivation for the experimental group using MATLAB supported learning in combination with a traditional lecture method and MATLAB supported learning in combination with collaborative method.

2. There is no significant mean difference between the components pre-motivation and post-motivation of the experimental groups using MATLAB supported learning in combination with collaborative method and that of the traditional lecture method.

\section{Material and Methods}

A quasi experimental designwas conducted to explore students' motivation through supporting the instructional approach with MATLAB software. The researchers adopted both pre- and post- motivation from Lius and Lin's work with a relevant edition [6]. The adopted motivation scale items were classified into three major components (i.e. value, expectancy and affect) whereas each component was again classified into different sub-components. Value was divided into three sub-components (i.e. intrinsic goal orientation (5 items), extrinsic goal orientation (6 - items) and task value (5 items)), expectancy was divided into two sub components (i.e. self efficacy for learning ( 6 - items) and beliefs for learning ( 5 - items)) and component of affect could be considered as anxiety (4 - items). Pre-motivation helps the researcher to know the motivation of the students to learn mathematics in 
general, whereas the post-motivation helps to know the students' motivation to learn mathematics using MATLAB software supported learning.

Two intact classes from school of engineering and technology department, Wolkite University, were chosen (Mechanical engineering group 1 and group 2). Both groups were selected through simple random sampling techniques. The number of students involved in this study was 30 and 29 that finally reduced into 27 and 26respectively. The reliability of pre-motivation was $\alpha=0.807$. The post -motivation item was an extension of pre-motivation to MATLAB supported learning method.

\section{Results and Discussion}

a. Descriptive statistics for Motivation

The general descriptive statistics for pre-motivation and post-motivation were given in order to investigate students' motivation towards learning mathematics and learning mathematics through MATLAB supported methods. The motivation was composed of six different components. Those are intrinsic, extrinsic, task value, belief, self-efficacy, and anxiety. Data were collected from Mechanical Engineering group one (MATLAB supported learning in combination with traditional lecture method group) and Mechanical Engineering group two (MATLAB supported learning in combination with collaborative method group). All students in those two intact classes were considered as a respondent. In general, the following Table 1 and Table 2 describe the details of descriptive statistics of pre- and post motivation respectively of both groups undergone through MATLAB supported learning.

Table 1. Descriptive statistics of the responses from both groups in Learning Mathematics.

\begin{tabular}{llllll}
\hline & Group & N & Mean & Std. Deviation & Std. Error Mean \\
\hline \multirow{2}{*}{ Pre-intrinsic } & Mechanical group 1 & 27 & 4.0667 & .46740 & .08995 \\
& Mechanical group 2 & 26 & 4.0385 & .48996 & .09609 \\
Pre-extrinsic & Mechanical group 1 & 27 & 3.8833 & .57183 & .11005 \\
& Mechanical group 2 & 26 & 3.6796 & .64126 & .12576 \\
Pre-task & Mechanical group 1 & 27 & 3.7704 & .67642 & .13018 \\
& Mechanical group 2 & 26 & 3.7231 & .69530 & .13636 \\
Pre-belief & Mechanical group 1 & 27 & 3.9200 & .66151 & .12731 \\
\multirow{3}{*}{ Pre-self } & Mechanical group 2 & 26 & 3.6208 & .70209 & .13769 \\
\multirow{3}{*}{ Pre-anxiety } & Mechanical group 1 & 27 & 3.5704 & .75997 & .14626 \\
\multirow{2}{*}{ Pre-total } & Mechanical group 2 & 26 & 3.5077 & .77816 & .15261 \\
& Mechanical group 1 & 27 & 3.3148 & .79841 & .15365 \\
& Mechanical group 2 & 26 & 3.1442 & .90325 & .17714 \\
\end{tabular}

Table 1 shows the mean, standard deviation and standard error for the pre-motivation. The table indicates that across all components of motivation (i.e. intrinsic, extrinsic, task value, belief, self-efficacy, and anxiety) mechanical engineering group 1 student has a higher mean score than mechanical engineering group 2 students. This reveals that before any treatment was given to both groups, mechanical engineering group 1 has better motivation than mechanical engineering group 2 to learn mathematics. The mean score of each component of motivation to learning mathematics is greater than $(M=3.00)$ and some of the variations range up-to 0.90325 which counteracts to demand further analysis.

Table 2. Descriptive statistics of the responses from both groups on learning Mathematics Supported by MATLAB.

\begin{tabular}{|c|c|c|c|c|c|}
\hline & Group & $\mathbf{N}$ & Mean & Std. Deviation & Std. Error Mean \\
\hline \multirow{2}{*}{ Post-intrinsic } & Mechanical group 1 & 27 & 3.5185 & 1.04109 & .20036 \\
\hline & Mechanical group 2 & 26 & 3.6692 & 1.03064 & .20212 \\
\hline \multirow{2}{*}{ Post-extrinsic } & Mechanical group 1 & 27 & 3.5489 & 1.02066 & .19643 \\
\hline & Mechanical group 2 & 26 & 3.7181 & .94173 & .18469 \\
\hline \multirow{2}{*}{ Post-task } & Mechanical group 1 & 27 & 3.8741 & .90833 & .17481 \\
\hline & Mechanical group 2 & 26 & 3.7308 & .90145 & .17679 \\
\hline Post-belief & Mechanical group 1 & 27 & 3.8693 & .89614 & .17246 \\
\hline \multirow{2}{*}{ Post-self } & Mechanical group 1 & 27 & 3.9407 & .90946 & .17503 \\
\hline & Mechanical group 2 & 26 & 3.5538 & .85287 & .16726 \\
\hline \multirow{2}{*}{ Post-anxiety } & Mechanical group 1 & 27 & 3.8889 & 1.09486 & .21071 \\
\hline & Mechanical group 2 & 26 & 3.3462 & .87772 & .17213 \\
\hline \multirow{2}{*}{ Post-total } & Mechanical group 1 & 27 & 3.7667 & .79556 & .15311 \\
\hline & mechanical group 2 & 26 & 3.6227 & .75908 & .14887 \\
\hline
\end{tabular}

Table 2 shows the mean, standard deviation and standard error for the post-motivation. The table indicates that across all components of motivation (i.e. intrinsic, extrinsic, task value, belief, self-efficacy, and anxiety) mechanical group 1 student has a higher mean score than mechanical group 2 students except on intrinsic and extrinsic motivation. This 
reveals that after treatments were given to each group, mechanical engineering group 1 got still better motivation than mechanical engineering group 2 to learn mathematics through MATLAB supported learning except on intrinsic and extrinsic motivation. This implies that MATLAB supported learning in combination with the collaborative learning approach is better to approach to increase students' intrinsic and extrinsic motivation. Besides, the mean score of each component of motivation to learning mathematics is greater than $(\mathrm{M}=3.00)$ and some of the variations range up-to 1.09486 which counteracts to demand further analysis.

\section{b. Inferential Statistics test for Motivation}

The motivation adapted from Liu and Linwas an ordinal data of five levels. The normality of the data was checked using skewness of the distribution for 31 items and all items lied between -1 and +1 . This indicates the data is distributed approximately normal. Therefore, the researcher can use parametric inferential statistics tests.

In order to test the hypothesis and compare the gain mean score of motivation and components of motivation of students in mathematics without using MATLAB supported learning which was a pre-motivation items and after MATLAB supported learning were employed. For the within group paired sample t-test and for the between groups of treatment an independent sample t-test were used.

$\mathrm{H}_{0[1]}$ : There is no significant mean difference between pre-motivational and post-motivational for the experimental group using MATLAB supported learning against the traditional lecture method group.

$\mathrm{H}_{0[2]}$ : There is no significant mean difference between components of pre-motivational and post-motivational for the experimental group using MATLAB supported learning against the traditional lecture method group.

The data collected from the respondents were independent and normally distributed. So, paired sample t-test was employed to compare the mean gain of the pre-motivation with the post-motivation of the experimental group using MATLAB supported learning with a traditional lecture method.

Table 3. Paired sample test of the mean scores of the pre-motivation and post-motivation within MATLAB supported learning with the traditional lecture method group.

\begin{tabular}{|c|c|c|c|c|c|c|c|c|}
\hline & & Mean & $\mathbf{N}$ & Std. & Std. Error & $\mathbf{T}$ & Df & $\mathbf{P}$ \\
\hline \multirow{2}{*}{ Pair 1} & Pre-intrinsic & 4.0667 & 27 & .46740 & .08995 & \multirow{2}{*}{2.678} & \multirow{2}{*}{26} & \multirow{2}{*}{.013} \\
\hline & Post-intrinsic & 3.5185 & 27 & 1.04109 & .20036 & & & \\
\hline \multirow{2}{*}{ Pair 2} & Pre-extrinsic & 3.8833 & 27 & .57183 & .11005 & \multirow{2}{*}{1.562} & \multirow{2}{*}{26} & \multirow{2}{*}{.130} \\
\hline & Post-extrinsic & 3.5489 & 27 & 1.02066 & .19643 & & & \\
\hline \multirow{2}{*}{ Pair 3} & Pre-task & 3.7704 & 27 & .67642 & .13018 & \multirow[t]{2}{*}{-.552} & \multirow[t]{2}{*}{26} & \multirow[t]{2}{*}{.585} \\
\hline & Post-task & 3.8741 & 27 & .90833 & .17481 & & & \\
\hline Pair 4 & Pre-belief & 3.9200 & 27 & .66151 & .12731 & .319 & 26 & .752 \\
\hline \multirow{2}{*}{ Pair 5} & Pre-self & 3.5704 & 27 & .75997 & .14626 & \multirow[t]{2}{*}{-1.788} & \multirow[t]{2}{*}{26} & \multirow[t]{2}{*}{.086} \\
\hline & Post-self & 3.9407 & 27 & 90946 & .17503 & & & \\
\hline \multirow{2}{*}{ Pair 6} & Pre-anxiety & 3.3148 & 27 & .79841 & .15365 & \multirow[t]{2}{*}{-2.586} & \multirow[t]{2}{*}{26} & \multirow[t]{2}{*}{.016} \\
\hline & Post-anxiety & 3.8889 & 27 & 1.09486 & .21071 & & & \\
\hline \multirow{2}{*}{ Pair 7} & Pre-total & 3.7737 & 27 & .41587 & .08003 & \multirow[t]{2}{*}{.048} & \multirow[t]{2}{*}{26} & \multirow[t]{2}{*}{.962} \\
\hline & Post-total & 3.7667 & 27 & .79556 & .15311 & & & \\
\hline
\end{tabular}

The administered pre- and post-motivational to examine the students' motivation toward learning mathematics and learning mathematics using MATLAB supported learning in combination with traditional lecture method ranging from 1 (strongly disagree) to 5 (strongly agree) were used as they are for positive statements and reversed for the negative statements assigning 1 (strongly agree) to 5 (strongly disagree). From the paired samples statistics the mean scores of both pre-motivation and post-motivation of students were above 3 indicating that students have good motivation for both learning mathematics and learning mathematics supported by MATLAB.

Table 3 shows that the total means of the pre-motivational $(\mathrm{M}=3.7737)$ is almost the same as the total means of the post motivational $(\mathrm{M}=3.7667)$. However, the paired sample t-test between pre- and post-motivation of students show that $t$ $(26)=.048, p=.962$ and this indicates there is no significant difference between the mean scores of pre- and post-motivation of students learning through MATLAB supported learning with a traditional lecture method.

Regarding components of the motivation scale, Table 3 shows that the paired sample t-test value are $\mathrm{t}(26)=2.678$, $\mathrm{p}=.013$ for intrinsic and $\mathrm{t}(26)=-2.586, \mathrm{p}=.016$ for anxiety. This indicates that there is a significant mean difference between pre-intrinsic and post-intrinsic motivation, and similarly, there is a significant mean difference between pre-anxiety and post-anxiety components of motivation.

The result in Table 3 shows that students' motivation to learn mathematics did not show significant improvement after they exposed to MATLAB technology. This shows that students have lacked the motivation to use MATLAB software in the teaching and learning platform because they were beginners to use MATLAB software in the classroom to learn mathematics. Mathematical software, whether being in a programming way or teaching the topics in various effects (like graph, computation, etc.) can be facilitated not only for the comprehension of mathematical concepts but also for increasing the motivation of students and the trust of oneself [16]. In contrast, the result of this study reveals that there is no significant mean difference between students' motivation. This might be due to various reasons some of which could be lack of students' experience and they are new to such kinds of 
instructional environments.

Table 4. Paired sample test of the mean scores of the pre-motivation and post-motivation within MATLAB supported learning with a collaborative method group.

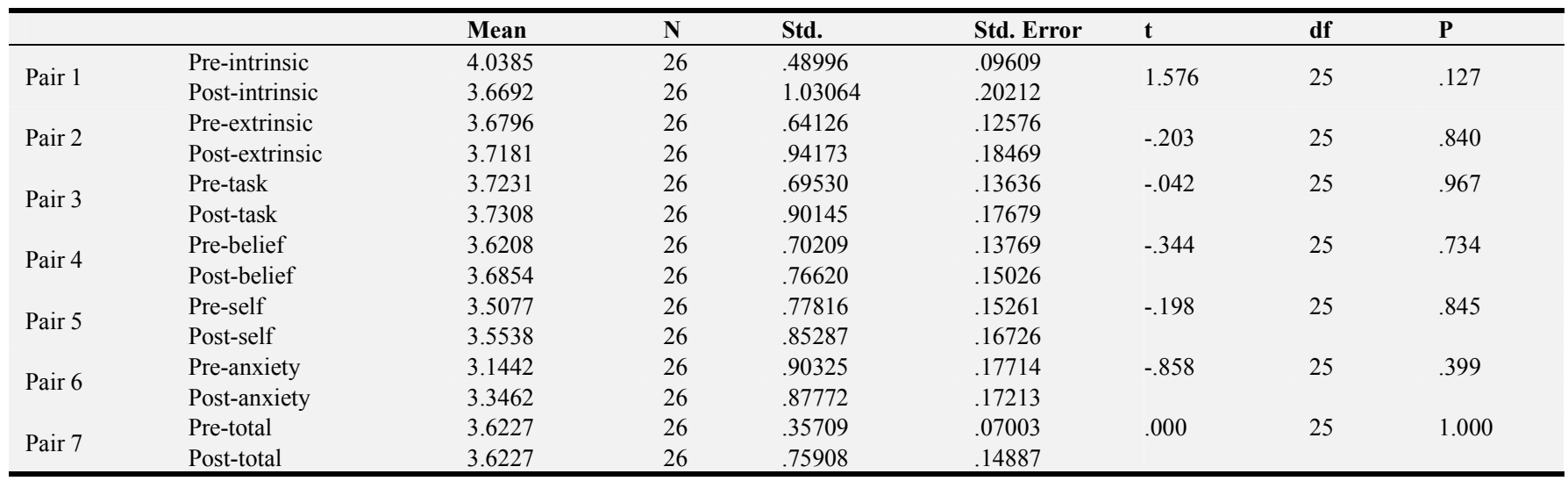

The following hypotheses show the difference between pre-motivation and post-motivation for MATLAB supported learning in combination with a collaborative method

$\mathrm{H}_{0[3]}$ : There is no significant mean difference between pre-motivational and post-motivational for the experimental group using MATLAB supported learning with collaborative method.

$\mathrm{H}_{0[4]}$ : There is no significant mean difference between components of pre-motivational and post-motivational for the experimental group using MATLAB supported learning with collaborative method.

The data collected from the respondents were independent and normally distributed. So, paired sample t-test was employed to compare the mean gain of the pre-motivation with the post-motivation of the experimental group using MATLAB supported learning with the collaborative method [12].

The data for pre- and post-motivational to examine the students' motivation toward learning mathematics and learning mathematics using MATLAB supported learning in combination with collaborative method ranging from 1 (strongly disagree) to 5 (strongly agree) for positive statements and vice-versa for negative statements that is 1 (strongly agree) to 5 (strongly disagree). Paired samples Statistics shows the mean scores of both pre-motivation and post-motivation of students were above 3 . Table 4 shows that the total means of the pre-motivational $(M=3.6227)$ is almost the same as the total means of the post motivational $(\mathrm{M}=3.6227)$. This indicates that students seem to have the same level of motivation for both learning mathematics through conventional methods and learning mathematics through MATLAB supported approaches.

The paired sample t-test between pre- and post-motivation of student shows that $\mathrm{t}(25)=.000, \mathrm{p}=1.000$ which indicates that there is no significant difference between mean scores of pre- and post-motivation. This result shows that students' motivation to learn mathematics and learning mathematics supported by MATLAB technology is almost the same. This result disagrees with the research work of Taleba, Ahmadib, and Musavi which indicates the utilization of mathematical software in the classroom increasing the motivation of students [16].

Moreover, the researchers tried explore if the result is same across the components of motivation. For this purpose the researchers used an independent sample t-test in order to test the significance of the mean difference between pre- and post motivation of MATLAB supported learning in combination with the collaborative method and traditional lecture method. The following hypotheses were examined.

$\mathrm{H}_{0[5]}$ : There is no significant mean difference between pre-motivation for the experimental groups using MATLAB supported learning in combination with collaborative method and traditional lecture method.

$\mathrm{H}_{0[6]}$ : There is no significant mean difference between components of pre-motivation for the experimental groups using MATLAB supported learning in combination with collaborative method and traditional lecture method.

Table 5. Independent sample test of the mean difference of the pre-motivation of MATLAB supported learning with traditional lecture method and MATLAB supported learning with collaborative method.

\begin{tabular}{|c|c|c|c|c|c|c|c|c|}
\hline & Group & $\mathbf{N}$ & Mean & Std. & Std. Error & $\mathbf{t}$ & df & $\mathbf{P}$ \\
\hline \multirow{2}{*}{ Pre-intrinsic } & Mechanical group 1 & 27 & 4.0667 & .46740 & .08995 & \multirow[t]{2}{*}{.214} & \multirow[t]{2}{*}{51} & \multirow[t]{2}{*}{.831} \\
\hline & Mechanical group 2 & 26 & 4.0385 & .48996 & .09609 & & & \\
\hline \multirow[t]{2}{*}{ Pre-extrinsic } & Mechanical group 1 & 27 & 3.8833 & .57183 & .11005 & \multirow[t]{2}{*}{1.222} & \multirow[t]{2}{*}{51} & \multirow[t]{2}{*}{.227} \\
\hline & Mechanical group 2 & 26 & 3.6796 & .64126 & .12576 & & & \\
\hline \multirow[t]{2}{*}{ Pre-task } & Mechanical group 1 & 27 & 3.7704 & .67642 & .13018 & \multirow[t]{2}{*}{.251} & \multirow[t]{2}{*}{51} & \multirow[t]{2}{*}{.803} \\
\hline & Mechanical group 2 & 26 & 3.7231 & .69530 & .13636 & & & \\
\hline Pre-belief & Mechanical group 1 & 27 & 3.9200 & .66151 & .12731 & 1.598 & 51 & .116 \\
\hline Pre-self & Mechanical group 1 & 27 & 3.5704 & .75997 & .14626 & .297 & 51 & .768 \\
\hline
\end{tabular}




\begin{tabular}{|c|c|c|c|c|c|c|c|c|}
\hline & Group & $\mathbf{N}$ & Mean & Std. & Std. Error & $\mathbf{t}$ & df & $\mathbf{P}$ \\
\hline \multirow{3}{*}{ Pre-anxiety } & Mechanical group 2 & 26 & 3.5077 & .77816 & .15261 & \multirow{3}{*}{.729} & \multirow{3}{*}{51} & \multirow{3}{*}{.469} \\
\hline & Mechanical group 1 & 27 & 3.3148 & .79841 & .15365 & & & \\
\hline & Mechanical group 2 & 26 & 3.1442 & .90325 & .17714 & & & \\
\hline \multirow[t]{2}{*}{ Pre-total } & Mechanical group 1 & 27 & 3.7737 & .41587 & .08003 & \multirow[t]{2}{*}{1.416} & \multirow[t]{2}{*}{51} & \multirow[t]{2}{*}{.163} \\
\hline & Mechanical group 2 & 26 & 3.6227 & .35709 & .07003 & & & \\
\hline
\end{tabular}

Table 5 shows that the mean of Mechanical group one students (learned through MATLAB supported learning in combination with the traditional lecture method) had a greater mean score than that of Mechanical group 2 students (learned through MATLAB supported learning in combination with the collaborative method) across all components and total motivation. From the same table, an independent sample t-test indicates that each component and total motivation were not statistically significant differences between groups on learning mathematics.

Moreover, the analysis of the post-motivation among MATLAB supported groups were tested using independent sample t-test across Mechanical group one that learned through MATLAB supported learning in combination with traditional lecture method and Mechanical group 2 learning through MATLAB supported learning in combination with the collaborative method. For this purpose, the following hypotheses were checked.

$\mathrm{H}_{0[7]}$ : There is no significant mean difference between post-motivational for the experimental groups using MATLAB supported learning in combination with the traditional lecture method and collaboration method.

$\mathrm{H}_{0[8]}$ : There is no significant mean difference between the components of post-motivational for the experimental groups using MATLAB supported learning in combination with the traditional lecture method and collaboration method.

Table 6. Independent sample test of the mean difference of the post-motivation of MATLAB supported learning with traditional lecture method and MATLAB supported learning with collaborative method.

\begin{tabular}{|c|c|c|c|c|c|c|c|c|}
\hline & Group & $\mathbf{N}$ & Mean & Std. & Std. Error & $\mathbf{t}$ & Df & $\mathbf{P}$ \\
\hline \multirow{2}{*}{ Post-intrinsic } & Mechanical group 1 & 30 & 3.5185 & 1.04109 & .20036 & \multirow[b]{2}{*}{-.529} & \multirow{2}{*}{51} & \multirow{2}{*}{.599} \\
\hline & Mechanical group 2 & 29 & 3.6692 & 1.03064 & .20212 & & & \\
\hline Post-extrinsic & Mechanical group 1 & 27 & 3.5489 & 1.02066 & .19643 & -.627 & 51 & .534 \\
\hline \multirow[t]{2}{*}{ Post-task } & Mechanical group 1 & 27 & 3.8741 & .90833 & .17481 & \multirow[t]{2}{*}{.576} & \multirow[t]{2}{*}{51} & \multirow[t]{2}{*}{.567} \\
\hline & Mechanical group 2 & 26 & 3.7308 & .90145 & .17679 & & & \\
\hline Post-belief & Mechanical group 1 & 27 & 3.8693 & .89614 & .17246 & .801 & 51 & .427 \\
\hline \multirow[t]{2}{*}{ Post-self } & Mechanical group 1 & 27 & 3.9407 & .90946 & .17503 & \multirow[t]{2}{*}{1.596} & \multirow[t]{2}{*}{51} & \multirow[t]{2}{*}{.117} \\
\hline & Mechanical group 2 & 26 & 3.5538 & .85287 & .16726 & & & \\
\hline \multirow[t]{2}{*}{ Post-anxiety } & Mechanical group 1 & 27 & 3.8889 & 1.09486 & .21071 & \multirow[t]{2}{*}{1.986} & \multirow[t]{2}{*}{51} & \multirow[t]{2}{*}{.052} \\
\hline & Mechanical group 2 & 26 & 3.3462 & .87772 & .17213 & & & \\
\hline \multirow[t]{2}{*}{ Post-total } & Mechanical group 1 & 27 & 3.7667 & .79556 & .15311 & \multirow[t]{2}{*}{.674} & \multirow[t]{2}{*}{51} & \multirow[t]{2}{*}{.504} \\
\hline & Mechanical group 2 & 26 & 3.6227 & .75908 & .14887 & & & \\
\hline
\end{tabular}

Table 6 shows that the mean of Mechanical group one students (who learned through MATLAB supported learning in combination with the traditional lecture method) had a greater mean score than Mechanical group 2 students (who learned through MATLAB supported learning in combination with the collaborative method) across all components of motivation except for intrinsic and extrinsic motivation. From the same table, an independent sample t-test indicated, t-values for each component of motivation were not statistically significant differences between groups on learning mathematics supported by MATLAB in combination with the traditional lecture method. This implies that learning mathematics supported by MATLAB does not motivate students. This could be because students were novices for technology-supported learning in general and MATLAB supported learning in particular. In contrast to this result, a prior study revealed that the utilization of software technology increases students' motivation. There is a positive relationship between technology and students, and also there is a direct association between motivation and learning mathematics [18]. Technology increases motivation and retention of subject matters [19]. Such a contending results need to be explored further to help explore associated predictors of variation.

\section{Conclusion}

There is no significant difference between the mean scores of pre-motivation and post- motivation within MATLAB supported learning in combination with the traditional lecture method. Similarly, there is no significant mean difference between components of motivation within MATLAB supported learning in combination with traditional lecture method except between pre-intrinsic and post-intrinsic motivation, and between pre-anxiety and post-anxiety components of motivation.

There is no significant difference between the mean scores of pre-motivation and post- motivation within MATLAB supported learning in combination with the collaborative method. Similarly, there is no significant mean difference between components of motivation within MATLAB supported learning in combination with the collaborative method.

There is also no significant difference between the mean scores of pre-motivation and post- motivation between 
MATLAB supported learning groups before and after the intervention. Moreover, there is no significant difference between the mean scores of components of pre-motivation and post- motivation between MATLAB supported learning groups except for the affective part that is anxiety.

Literature indicates that statistical and mathematical software had a positive effect on students' motivation. In contrast to this, this study shows that supporting instructional approaches with MATLAB software did not bring a significant difference in students' motivation to learn mathematics. This might happen due to a lack of experience, and a lack of motivation to learn mathematics in general.

These also indicate the need for further investigation by dissociating the components of motivation and at expanded groups for the purpose of generalizability or identification of contextual factors of indication.

\section{References}

[1] Ozdamli, F., Karabey, D., \& Nizamoglu, B. (2012). The effect of technology supported collaborative learning settings on behavior of students towards Mathematics learning. 2nd World Conference on Educational Technology Researches.

[2] María Blanca Ibáñez M. B., Portillo A. U., Cabada R. Z., \& Barrón M. L. (2019). Impact of augmented reality technology on academic achievement and motivation of students from public and private Mexican schools. A case study in a middle-school geometry course. Computer \& Education 145 (2020), https://doi.org/10.1016/j.compedu.2019.103734.

[3] Persico, D., \& Pozzi, F. (2011). Task, Team and Time to structure online collaboration in learning environments. World Journal on Educational Technology, 3 (1), 1-15.

[4] Cheng L., Antonenko P. D., Ritzhaupt A. D., Dawson K., Miller D., MacFadden B. J., Grant C., Sheppard T. D., \&Ziegler M. (2020). Exploring the influence of teachers' beliefs and 3D printing integrated STEM instruction on students' STEM motivation. Computer \& Education 158 (2020) https://doi.org/10.1016/j.compedu.2020.103983.

[5] Sandybayev A. (2020). The Impact of E-Learning Technologies on Student's Motivation: Student Centered Interaction in Business Education. International Journal of Research in Tourism and Hospitality (IJRTH), Vol 6, no. 1, pp. 16-24. doi: http://dx.doi.org/10.20431/2455-0043.0601002.

[6] Liu, E. Z \& Lin, C. H. (2010). Survey Study of Mathematics Motivated Strategies for Learning Questionnaire (MMSLQ) for Grade 10-12 Taiwanese Students. The Turkish Online Journal of Educational Technology, 9 (2), 221-233.

[7] Yavuz, G., Ozyildirim, F. \& Dogan, N. (2012). Mathematics motivation scale: a validity and reliability. Procedia - Social and Behavioral Sciences 46, 1633-1638.
[8] Pintrich, P. R., \& De Groot, E. V. (1990). Motivational and Self-Regulated Learning Components of Classroom Academic Performance. Journal of Educational Psychology, 82, 33-40.

[9] Cavas, P. (2011). Factors affecting the motivation of Turkish primary students for science learning. Science Education International, 2 (1), 31-42.

[10] Lee, O., \& Brophy, J. (1996). Motivational patterns observed in sixth-grade science classrooms. Journal of Research in Science Teaching, 33 (3), 585-610.

[11] Rashid S. \&Rana R. A. (2019). Relationship between the Levels of Motivation and Learning Strategies of Prospective Teachers at Higher Education Level Bulletin of Education and Research April 2019, Vol. 41, No. 1 pp. 57-66.

[12] Pintrich, P., Smith, D., Garcia, T. \& McKeachie, W. (1991). A manual for the use of the motivated strategies for learning questionnaire (MSLQ). National Center for Research to Improve Post-Secondary Teaching and Learning.

[13] Aurah, M. C. (2013). The Effects of Self-efficacy Beliefs and Metacognition on Academic Performance: A Mixed Method Study. American Journal of Educational Research, 1 (8), 334-343.

[14] Mulugeta Atnafu (2012). Motivation, Social Support, Alienation from the School and their Impact on Students' Achievement in Mathematics: The Case of Tenth Grade Students. Ethiopian Journal of Education\& Science. 8 (1), 53-74.

[15] Ryan, R. M. \& Deci, E. L. (2000). Intrinsic and Extrinsic Motivations: Classic Definitions and New Directions. Contemporary Educational Psychology 25, 54-67. doi: 10.1006/ceps.1999.1020, available online at http://www.idealibrary.comon.

[16] Taleba, Z., Ahmadib, A., \& Musavi, M. (2015). The effect of $\mathrm{m}$-learning on mathematics learning. Procedia Social and Behavioral Sciences 171, 8-89.

[17] Francis J. (2017). The Effects of Technology on Student Motivation and Engagement in Classroom-Based Learning. All Theses and Dissertations, 121. http://dune.une.edu/theses/121.

[18] Shin, Y. E. \& Mills, D. (2007). Setting the New Standard with Mobile Computing in Online Learning. The International Review of Research in Open and Distance Learning, 8 (2).

[19] MacLuckie, J. (2010). Mobile learning for Mathematics: Nokia project in South Africa. Symbian tweet, http://www.symbiantweet.com/mobile-learning-for-Mathemati cs-in-south-africa.

[20] Ogbuanya T. C., \& Efuwape B. M (2018). Technology-aided learning environment: An investigation into electrical/electronic students' instructional preferences, attitude and approaches to learning. South African Journal of Education, Volume 38, Supplement 2, doi.org/10.15700/saje.v38ns2a1535. 